\title{
Suppression of GRP78 sensitizes human colorectal cancer cells to oxaliplatin by downregulation of CD24
}

\author{
JINGLE XI $^{1 *}$, YUFAN CHEN ${ }^{2 *}$, SHANGBIN HUANG $^{3}$, FEI CUI $^{1}$ and XINYING WANG ${ }^{4}$ \\ Departments of ${ }^{1}$ Oncology and ${ }^{2}$ Orthopaedic Surgery, Nanfang Hospital, Guangzhou, Guangdong 510515; \\ ${ }^{3}$ Department of General Surgery, Taixin Hospital, Dongguan, Guangdong 523000; ${ }^{4}$ Department of Gastroenterology, \\ Zhujiang Hospital, Southern Medical University, Guangzhou, Guangdong 510282, P.R. China
}

Received May 11, 2017; Accepted January 29, 2018

DOI: $10.3892 / \mathrm{ol} .2018 .8549$

\begin{abstract}
Glucose-regulated protein 78 (GRP78) is an endoplasmic reticulum stress signaling regulator with anti-apoptotic properties. It has been demonstrated to promote tumor proliferation, survival and metastasis, and to confer resistance against a large variety of therapies. CD24 is a glycosyl-phosphatidylinositol-anchored protein, which is known to have a role in tumor progression, particularly in colorectal cancer (CRC). In the present study, oxaliplatin (L-OHP) was demonstrated to decrease the expression of CD24 in HT29 cells. Knockdown of CD24 using small interfering RNA resulted in sensitization of HT29 cells to L-OHP. By contrast, overexpression of CD24 rendered SW480 cells resistant to L-OHP, which indicated that $\mathrm{CD} 24$ antagonized L-OHP-induced cytotoxicity. A co-immunoprecipitation assay revealed that GRP78 physically associates with CD24. L-OHP suppresses the expression of GRP78 and CD24, in part come from the inhibition of interaction between the two. Suppression of GRP78 caused downregulation of CD24 expression and enhanced L-OHP-induced CD24 inhibition. Furthermore, down-regulation of GPR78 with a pharmacological inhibitor sensitized the CRC cells to L-OHP. Collectively, the present results indicate that CD24 antagonizes L-OHP-induced cytotoxicity and that GRP78 is involved in this process. A novel mechanism via which $\mathrm{CRC}$ cells acquire resistance to $\mathrm{L}-\mathrm{OHP}$ was thereby revealed. Use of a combination of compounds which suppress GRP78 may help to improve the effectiveness of L-OHP in the treatment of CRC.
\end{abstract}

Correspondence to: Dr Xinying Wang, Department of Gastroenterology, Zhujiang Hospital, Southern Medical University, 253 Industrial Road, Haizhu, Guangzhou, Guangdong 510282, P.R. China

E-mail: 675176024@qq.com

${ }^{*}$ Contributed equally

Key words: glucose regulated protein 78, CD24, oxaliplatin, colorectal cancer

\section{Introduction}

CD24 is a glycosyl-phosphatidylinositol-anchored protein with a mucin-type structure that resides exclusively in membrane microdomains. CD24 is often highly expressed in human solid tumors (including lung, brain, gastric, pancreatic, colon, prostate, breast and ovarian cancers, cholangiocarcinoma, medulloblastoma and cutaneous malignant melanoma) and is associated with poor prognosis (1-6). Experimental studies performed over the last decade suggest a role of CD24 in tumor growth and processes associated with metastatic spread, including adhesion, migration and invasion (7-9). Downregulation of the expression of CD24 in vitro (using short-hairpin interfering RNA) and in vivo (using monoclonal antibodies) was demonstrated to decrease the viability of ovarian cancer cells and induce cell apoptosis $(10,11)$. In a study by Sagiv et al (9), knockdown of CD24 expression with the use of monoclonal antibodies or small interfering (si)RNA was demonstrated to inhibit growth and invasion of colorectal and pancreatic cancer cells. Suyama et al (12) also reported that CD24 gene transfer or inhibition of signal transducer and activator of transcription may represent a novel therapeutic strategy against refractory breast cancer. CD24+ cells were also demonstrated to exhibit enhanced chemoresistance as compared to CD24- subpopulations $(2,13)$. Furthermore, addition of SWA11 monoclonal antibody to inhibit CD24 expression strongly sensitized A549 lung cancer cells to gemcitabine (14).

However, the underlying mechanisms via which the expression of CD24 is regulated and the role of CD24 in tumor progression and chemoresistance have remained to be fully elucidated. None of the known CD24-associated proteins fully define the role of CD24 in chemotherapy. In previous work by our group, a series of potential CD24-interacting proteins was identified by using high-throughput mass spectrometry (data unpublished). These included glucose-regulated protein 78 (GRP78), which belongs to the family of heat shock proteins and is also referred to as immunoglobulin (Ig) heavy-chain binding protein (BiP). Elucidation of the association between CD24 and GRP78 may help define the role of CD24 in tumor progression and possibly the development of a novel approach to treat colorectal cancer (CRC).

GRP78 is a major endoplasmic reticulum (ER) chaperone with $\mathrm{Ca}^{2+}$ binding ability; it also serves as an ER stress signaling 
regulator (15). Upregulation of GRP78 expression in cancer cells has been reported in several cancer types, including those of the urinary, digestive, mammary, cerebral and respiratory systems, and osteosarcoma (16-19). The presence of GRP78 autoantibodies in the sera of cancer patients is generally associated with poor prognosis, as GRP78 promotes tumor cell proliferation, survival and metastasis by suppressing ER stress-induced apoptosis (20-25). Overexpression of GRP78 was also reported to correlate with chemoresistance. In recent studies, GRP78 was demonstrated to confer resistance against doxorubicin, bortezomib (26), VP-16 (27), temozolomide (28), paclitaxel and cisplatin (29). Furthermore, treatment with GRP78 inhibitor or knockdown of GRP78 was reported to potentiate chemotherapy-induced apoptosis in most of the cancer types mentioned above. However, the mechanisms by which GRP78 promotes malignant attributes of cancer cells have remained largely elusive. Of note, GRP78 and CD24 have a similar role in tumor progression and chemoresistance $(30,31)$. A previous study by our group identified GRP78 as a CD24-interacting protein, which suggests a possible link between the mechanism of action of GRP78 and CD24. Understanding the interaction between GRP78 and CD24 may lead to the further elucidation of the mechanisms of tumor progression.

\section{Materials and methods}

Cell lines. The HT29, HT8, SW480 and colo205 human CRC cell lines were obtained from the American Type Culture Collection (Manassas, VA, USA) and cultured in RPMI-1640 medium containing 10\% fetal calf serum (Bio Whittaker, Verviers, Belgium), 2 mM glutamine, $100 \mathrm{IU} / \mathrm{ml}$ penicillin and $100 \mu \mathrm{g} / \mathrm{ml}$ streptomycin (Cellgro; Mediatech Inc., Manassas, VA, USA) at $37^{\circ} \mathrm{C}$ in a humidified atmosphere containing $5 \% \mathrm{CO}_{2}$.

Chemicals and antibodies. Oxaliplatin (L-OHP) and the GRP78 inhibitor vomitoxin (VT) were purchased from Sigma-Aldrich (Merck KGaA, Darmstadt, Germany). L-OHP was stored as a $20 \mathrm{mM}$ solution in dimethyl sulfoxide (DMSO) at $-20^{\circ} \mathrm{C}$, and was diluted with RPMI 1640 medium prior to use with the highest concentration of DMSO in culture being $0.05 \%(\mathrm{v} / \mathrm{v})$. The rabbit polyclonal anti-GRP78/Bip antibody (cat no. ab21685) was purchased from Abcam Ltd (Cambridge, MA, USA). Anti-CD24-SWA11 monoclonal antibody used for immunoprecipitation (IP) was obtained from Professor Hans-Peter Altevogt (Department of Translational Immunology, German Cancer Research Center, Heidelberg, Germany), in whose lab the antibody was generated (32). Anti-CD24 monoclonal antibody (cat. no. SC-7034) used for western blotting and IP, $\beta$-actin antibody (cat. no. SC130301) and horseradish peroxidase-conjugated goat anti-rabbit IgG (cat. no. SC2004) were purchased from Santa Cruz Biotechnology, Inc. (Dallas, TX, USA).

Plasmids and small interfering (si)RNA. Full-length human CD24 was amplified by polymerase chain reaction (PCR). The primers for CD24 were as follows: Forward, 5'-GTTGTTGGA TCCATGGGCAGAGCAATGGT-3' and reverse, 5'-GTTGTT CTCGAGcgAGAGTAGAGATGCAGAAGAGAG-3'. The
pcDNA4-CD24-myc plasmid (33) was constructed by inserting this PCR product into the pcDNA4 Myc-His B vector (Invitrogen; Thermo Fisher Scientific, Inc., Waltham, MA, USA) and verified by sequencing. GRP78 siRNA (siGENOME SMART pool GRP78; cat. no. M-008198-01) and control siRNA (siGENOME Non-Targeting siRNA Pool \#1; cat. no. D-001206-13-20) were obtained from Dharmacon (Lafayette, CO, USA). The sequences of the CD24 siRNA and control siRNA were 5'-UCUCUCUUCUGCAUCUUU AdTdT-3' and 5'-CUACCUAUGCAGAUUUAUUdTdT-3', respectively. Transfection of siRNAs was performed using the Lipofectamine ${ }^{\circledR} 2000$ reagent (Invitrogen; Thermo Fisher Scientific, Inc.) according to the manufacturer's protocols.

Cell viability assay. Cell viability was determined using a CellTiter-Blue assay kit (Promega Corp., Madison, WI, USA), according to the manufacturer's instructions. In brief, cells were seeded in 96-well plates at a density of $4 \times 10^{3}$ cells/well and allowed to attach for $24 \mathrm{~h}$ followed by exposure to L-OHP at different concentrations $(1,2.5,5$ and $10 \mu \mathrm{M})$ for 12, 24 or 48 h. Subsequently, $20 \mu$ l CellTiter-Blue reagent was added into each well and the cells were incubated for another $2 \mathrm{~h}$ at $37^{\circ} \mathrm{C}$. The fluorescence was then recorded $\left[540_{\mathrm{Ex}} / 600_{\mathrm{Em}}\right]$ using a fluorescence plate reader (BioTek Synergy 2; BioTek, Winooski, VT, USA). Assays were performed in triplicate for each experiment and the mean cell viability was normalized to that in the vehicle (DMSO)-treated controls. Each experimental data-point was generated from at least three independent experiments.

Colony forming assay. 500 HT29 cells were seeded in each hole of 6-hole plate. HT29 cells were treated with or without GRP78 inhibitor VT $(1 \mu \mathrm{g} / \mathrm{ml})$ for $2 \mathrm{~h}$, followed by incubation with different concentrations of L-OHP or vehicle (DMSO) for another $24 \mathrm{~h}$. The medium was refreshed and the cells were incubated at $37^{\circ} \mathrm{C}$ in an atmosphere with $95 \%$ humidity containing $5 \% \mathrm{CO}_{2}$ for 14 days. The cells were stained with crystal violet for $30 \mathrm{mins}$ at room temperature and the number of colonies was counted. At least three independent experiments were performed for each treatment. The results were expressed as a percentage of colony growth relative to that in the control group.

Co-IP and western blot analysis. Total protein lysates of HT29 cells were obtained by incubation on ice for $30 \mathrm{~min}$ in IP/lysis buffer [50 mM 4-(2-hydroxyethyl)-1-piperazineethanesulfonic acid, $\mathrm{pH}$ 7.5, $150 \mathrm{mM} \mathrm{NaCl}, 5$ mM EDTA, 1\% Triton X-100, $1 \mathrm{mM}$ phenylmethyl sufonylfluoride, $2 \mu \mathrm{g} / \mathrm{ml}$ pepstatin A and $1 \mathrm{X}$ protease inhibitor cocktail (Sigma-Aldrich; Merck KGaA, Darmstadt, Germany)], followed by centrifugation at $15,000 \mathrm{x} \mathrm{g}$ for $20 \mathrm{~min}$ at $4^{\circ} \mathrm{C}$. Subsequently, $25 \mu 1$ protein $\mathrm{G}$ beads (Zymed; Thermo Fisher Scientific, Inc.) were added to preclear the supernatant at $4^{\circ} \mathrm{C}$ for $1 \mathrm{~h}$, followed by centrifugation at $1000 \mathrm{x} \mathrm{g}$ at $4^{\circ} \mathrm{C}$ for $10 \mathrm{~min}$. The supernatant was stored and protein concentration was assessed. The samples were then incubated with 5-10 $\mu \mathrm{g}$ of the indicated antibody or control mouse IgG (Pierce; Thermo Fisher Scientific, Inc.) for $1 \mathrm{~h}$ at $4^{\circ} \mathrm{C}$ and then with $30 \mu \mathrm{l}$ protein $\mathrm{G}$ beads for $2 \mathrm{~h}$ at $4^{\circ} \mathrm{C}$. After 4 washes in IP/lysis buffer, the beads were boiled in $40 \mu 1$ of $2 \mathrm{X}$ Laemmli buffer for $5 \mathrm{~min}$ and the eluted proteins 
(30 $\mu \mathrm{g} /$ lane) were subjected to $12.5 \%$ SDS-PAGE. After the separation, the proteins were transferred onto polyvinylidene difluoride membranes (Bio-Rad Laboratories, Inc., Hercules, CA, USA). The membrane was blocked in 5\% non-fat milk in $1 \%$ Tris-buffered saline containing $0.1 \%$ Tween-20 (TBST) for $1 \mathrm{~h}$ at room temperature, and then probed separately with primary antibodies (1:500) overnight at $4^{\circ} \mathrm{C}$. Subsequently, the membranes were washed thrice for $10 \mathrm{~min}$ with TBST and incubated with the appropriate secondary antibody (cat. no. SC2004) for $1 \mathrm{~h}$ at room temperature. After 3 washes, the immunostained proteins were detected by chemiluminescence (Pierce $^{\mathrm{TM}}$ ECL Western Blotting Substrate, cat. no. 32106; Thermo Fisher Scientific, Inc.).

Statistical analysis. GraphPad Prism 5 software (GraphPad Software, Inc., La Jolla, CA, USA) was used for data processing. For the colony formation assay, data were analyzed with Microsoft ${ }^{\circledR}$ Excel (version 14.0.7180.5002, Microsoft Corp., Redmond, WA, USA) and plotted in Prism 5. Values are expressed as the mean \pm standard deviation or standard error as indicated. Differences between groups were evaluated using one-way analysis of variance. Multiple comparisons between the groups were performed using the Student-Neuman-Keuls test. $\mathrm{P}<0.05$ was considered to indicate a statistically significant difference.

\section{Results}

L-OHP decreases CD24 expression in CRC cells. First, the expression of CD24 was assessed in a panel of CRC cell lines, including SW480, colo205, HCT8 and HT29, using immunoblotting analysis. The results indicated that the CRC cell lines expressed varying levels of CD24. The HT29 and colo205 cell lines had high expression levels of CD24, while the expression was undetectably low in SW480 and HCT8 cells (Fig. 1A).

To assess the effect of L-OHP on CD24 expression, HT29 cells were treated with vehicle or L-OHP at various concentrations for $24 \mathrm{~h}$. The expression of CD24 was determined using western blot analysis. As presented in Fig. 1B, the protein levels of CD24 in HT29 cells treated with L-OHP at 1, 2.5 and $5 \mu \mathrm{M}$ were decreased to 63,51 and $21 \%$, respectively, compared with those in the DMSO vehicle control. These results suggested that L-OHP decreased the expression of CD24 in a dose-dependent manner. An L-OHP dose of $5 \mu \mathrm{M}$ was chosen for further experiments.

CD24 antagonizes L-OHP-induced cytotoxicity. HT29 CRC cells were treated with different concentrations of L-OHP $(1,2.5,5$ or $10 \mu \mathrm{M})$ for 12,24 or $48 \mathrm{~h}$. As presented in Fig. 2A, the concentration leading to a $50 \%$ reduction in the cell number $\left(\mathrm{IC}_{50}\right)$ of L-OHP at 12,24 and $48 \mathrm{~h}$ was determined as $22.35 \pm 1.295,19.89 \pm 0.815$ and $6.683 \pm 0.0363 \mu \mathrm{M}$, respectively. The cytotoxic effect of L-OHP on HT29 cells with high expression of CD24 and SW480 cells with low expression of CD24 was then compared. The $\mathrm{IC}_{50}$ was $19.89 \pm 0.815$ and $4.13 \pm 0.245 \mu \mathrm{M}$, respectively (Fig. $2 \mathrm{~A}$ and $\mathrm{B}$ ). To determine the role of CD24 in L-OHP-induced cytotoxicity, CD24 expression in HT29 cells was knocked down using specific targeted siRNA. HT29 cells were transfected with vehicle siRNA or CD24 siRNA, and then incubated with different

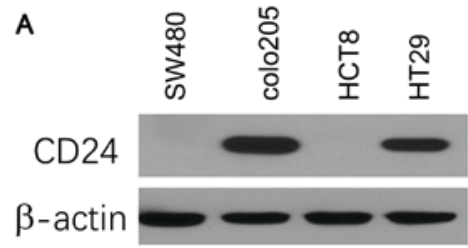

B L-OHP

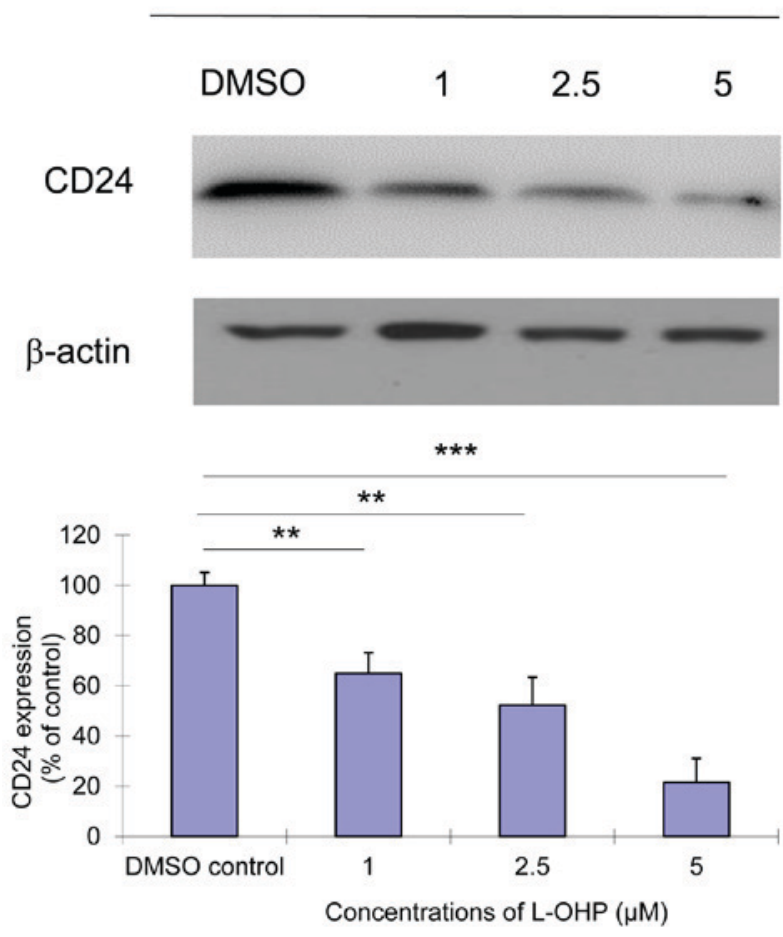

Figure 1. L-OHP decreases the expression of CD24 in a dose-dependent manner in colorectal cancer cells. (A) Expression of CD24 in colorectal cancer cell lines SW480, colo205, HCT8 and HT29. (B) L-OHP decreased the expression of CD24 in HT29 cells. HT29 cells were treated with DMSO as a vehicle or the indicated concentrations of $\mathrm{L}-\mathrm{OHP}(1,2.5,5 \mu \mathrm{M})$ for $24 \mathrm{~h}$ and CD24 expression was assessed by western blot analysis. Whole-cell lysates were subjected to western blot analysis. The protein band intensity was normalized to $\beta$-actin. Images are representative of three individual experiments. Values are expressed as the mean \pm standard deviation $(n=3)$. The basal level of CD24 expression in the vehicle-treated control was set as $100 \%$. ${ }^{* *} \mathrm{P}<0.01$ and ${ }^{* * * *} \mathrm{P}<0.001$ vs. DMSO vehicle control group. L-OHP, oxaliplatin; DMSO, dimethyl sulfoxide.

concentrations of L-OHP for $24 \mathrm{~h}$. As presented in Fig. 2C, CD24 siRNA decreased the $\mathrm{IC}_{50}$ of L-OHP from $19.89 \pm 0.815$ to $3.998 \pm 0.042 \mu \mathrm{M}$. Vehicle siRNA had almost no effect on the cytotoxicity of L-OHP. The effect of ectopic CD24 expression on the cytotoxic effect of L-OHP was then examined in SW480 cells, which were transiently transfected with a CD24 expression plasmid, pcDNA4-CD24-myc plasmid, or a vehicle control plasmid. SW480 cells were observed to develop resistance to L-OHP after transfection with $\mathrm{CD} 24$ expression plasmid; the $\mathrm{IC}_{50}$ increased from $4.13 \pm 0.25$ to $9.90 \pm 0.43 \mu \mathrm{M}$ (Fig. 2D).

Effect of L-OHP on GRP78 and CD24. To elucidate the underlying regulatory mechanisms associated with $\mathrm{CD} 24$, it was attempted to identify proteins associated with IT, as to date, none of the known CD24-associated proteins has provided any insight into its role in the response or resistance to chemotherapy, to the 
A
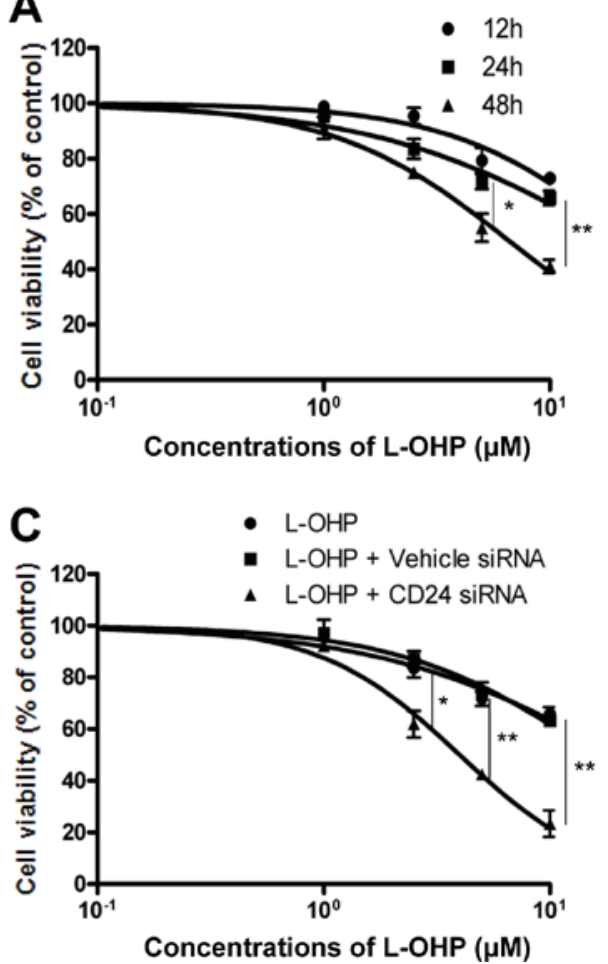

B
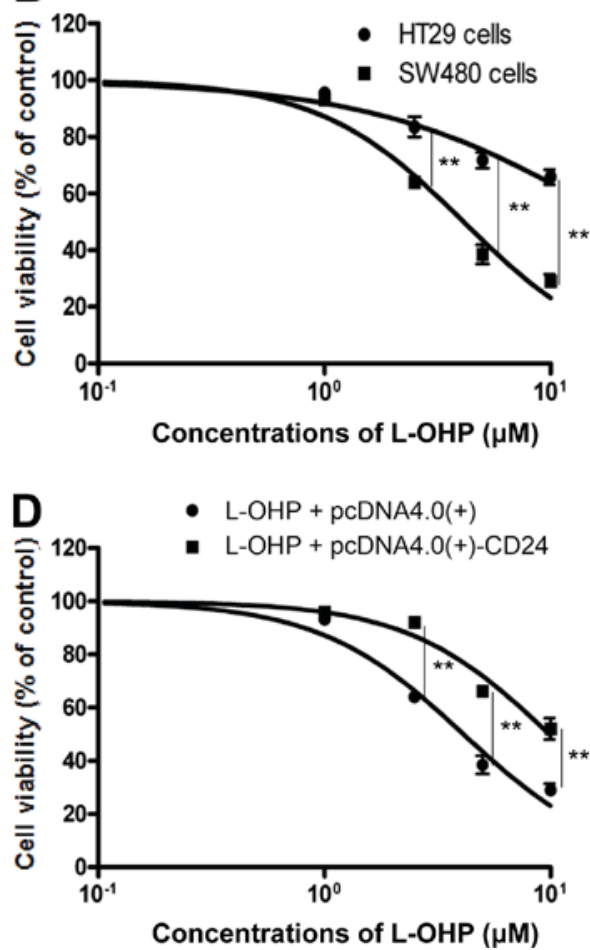

Figure 2. (A) Dose-response cytotoxicity of L-OHP in HT29 colorectal cancer cells. HT29 cells were treated with different concentrations of L-OHP (1, 2.5, 5 and $10 \mu \mathrm{M}$ ) for 12,24 and $48 \mathrm{~h}$. The cell viability was then evaluated with the CellTiter-Blue assay. There is statistical significance between the cell viability of 24 and $48 \mathrm{~h}\left({ }^{*} \mathrm{P}<0.05,{ }^{* *} \mathrm{P}<0.01\right)$. (B) Cytotoxicity of L-OHP in HT29 and SW480 cells. HT29 and SW480 cells received the same treatment with L-OHP for $24 \mathrm{~h}$ and the cell viability was evaluated. Statistical significance between HT29 cells and SW480 cells ( ${ }^{* *}$ P<0.01). (C) Knockdown of CD24 sensitizes HT29 cells to L-OHP. HT29 cells were transfected with either a non-targeting siRNA (control siRNA) or a CD24-specific siRNA sequence at 100 nM for $24 \mathrm{~h}$. Transfected cells were then treated with different concentrations of L-OHP for another 24 h. Statistical significance between cells transfected with a CD24-specific siRNA sequence and the other two groups $\left({ }^{*} \mathrm{P}<0.05,{ }^{* *} \mathrm{P}<0.01\right)$. (D) Upregulation of CD24 rendered SW480 cells resistant to L-OHP. SW480 cells were transfected with either empty vector or vector expressing CD24. At $48 \mathrm{~h}$ after transfection, the cells were used for the experiments. Native SW480 and transfected cells were treated with different concentrations of L-OHP for $24 \mathrm{~h}$. Statistical significance compared with control cells $\left(^{* *} \mathrm{P}<0.01\right)$. Cell viability was evaluated with the CellTiter-Blue assay. Assays were performed in triplicate for each experiment; the mean cell viability at each concentration is expressed as a percentage of that in the dimethyl sulfoxide-treated control. Each data-point represents the mean of triplicate independent experiments, and error bars indicate the standard error. L-OHP, oxaliplatin; siRNA, small interfering RNA.

best of our knowledge. In previous work by our group, a series of CD24-associated proteins was identified (data unpublished), and further research focused on the proteins involved in chemotherapy. Co-IP was performed to further verify the physical association between GRP78 and CD24 indicated in the previous study. As presented in Fig. 3A, the co-IP assay demonstrated that endogenous CD24 associated with endogenous GRP78 in HT29 cells. To investigate the effect of L-OHP on the interaction between GRP78 and CD24, HT29 cells were treated with $5 \mu \mathrm{M}$ L-OHP and the interaction was assessed using a co-IP assay. The results demonstrated that GRP78 physically associated with CD24 in HT29 cells and that L-OHP suppressed the expression of GRP78 and CD24 (Fig. 3B).

Suppression of GRP78 decreases the expression of CD24 and enhances L-OHP-induced cytotoxicity. To assess whether altered levels of GRP78 affect CD24 expression, First, HT29 cells were treated with GRP78 inhibitor VT at $1 \mu \mathrm{g} / \mathrm{ml}$ for $2 \mathrm{~h}$, then treated with L-OHP at $5 \mu \mathrm{M}$ for $24 \mathrm{~h}$. Then CD24 and GRP78 expression were determined by western blot analysis. As presented in Fig. 4, VT caused a significant downregulation of CD24 expression in HT29 cells with or without L-OHP treatment. L-OHP significantly decreased the expression of CD24, and that of GRP78 to a slightly lesser extent. Furthermore, inhibition of GRP78 by VT potentiated the inhibition of CD24 by L-OHP.

The cell viability assay and colony forming assay confirmed the indication that suppression of GRP78 sensitized HT29 cells to L-OHP-induced cytotoxicity. As presented in Fig. 5A, suppression of GRP78 using VT resulted in a significant decrease in the amount of viable cells; the $\mathrm{IC}_{50}$ of L-OHP alone and in combination with VT was $19.89 \pm 0.82$ and $5.216 \pm 0.63 \mu \mathrm{M}$, respectively. In the colony forming assay, after exposure to $1 \mu \mathrm{g} / \mathrm{ml} \mathrm{VT}$ for $2 \mathrm{~h}$, HT2 9 cells were treated with various concentrations of L-OHP for $24 \mathrm{~h}$ and then incubated for another 10-14 days, followed by determination of the number of colonies. The $\mathrm{IC}_{50}$ of L-OHP alone and in combination with VT was $4.695 \pm 1.02$ and $2.97 \pm 0.96 \mu \mathrm{M}$, respectively (Fig. 5B). The $\mathrm{IC}_{50}$ values obtained in the colony forming assay were lower than those of the cytotoxicity assay, which indicated that certain cells were inhibited, losing their ability to proliferate, and form colonies. The colony assay determines the cologenicity of cells, which act as seed cells to form metastasis or recurrent tumors, while the cell viability assay may reflect the acute effect of the drug on the primary tumor. The results of the colony forming assay are likely to be more representative of the scenario of an in vivo experiment than the cell viability assay. 
A

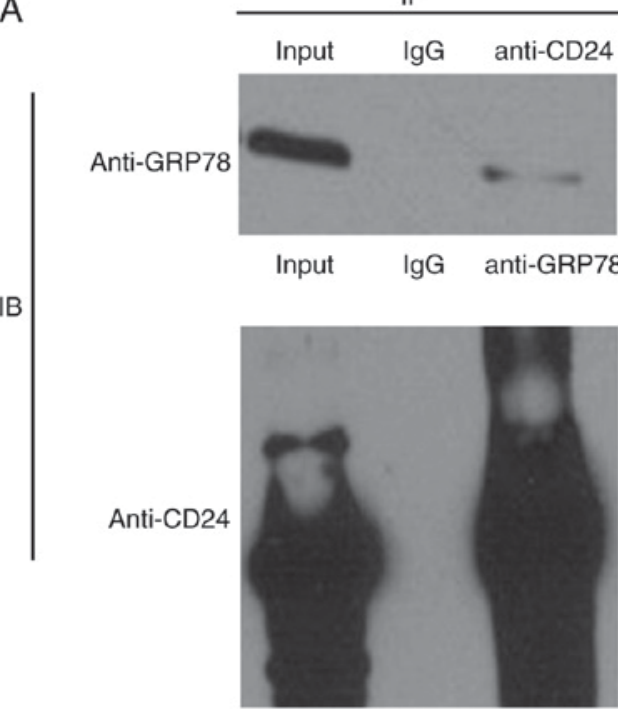

B

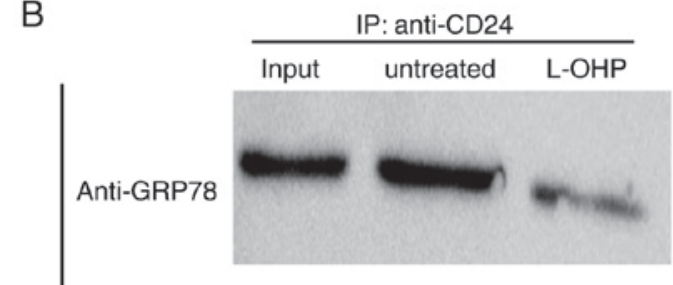

IB

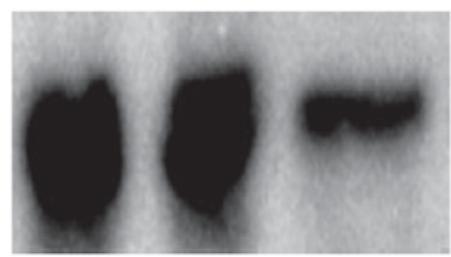

Figure 3. Physical interaction between GRP78 and CD24. (A) Upper panel: IP with CD24 using anti-CD24 antibody and IB detection with anti-GRP78 antibody. Lower panel: IP with GRP78 using anti-GRP78 antibody and IB detection with anti-CD24 antibody. Whole-cell lysates of HT29 cells were subjected to IP. The levels of GRP78 and CD24 in the resulting precipitates were determined by western blot analysis. IgG was used as a control albumin. (B) Whole-cell lysates from HT29 cells with or without L-OHP treatment $(5 \mu \mathrm{M}, 24 \mathrm{~h})$ were subjected to IP with CD24 antibodies. The levels of GRP78 and CD24 in the resulting precipitates were determined by western blot analysis. Images are representative of three independent experiments. GRP78, glucose-regulated protein 78; IP, immunoprecipitation; IB, immunoblot; IgG, immunoglobulin G.

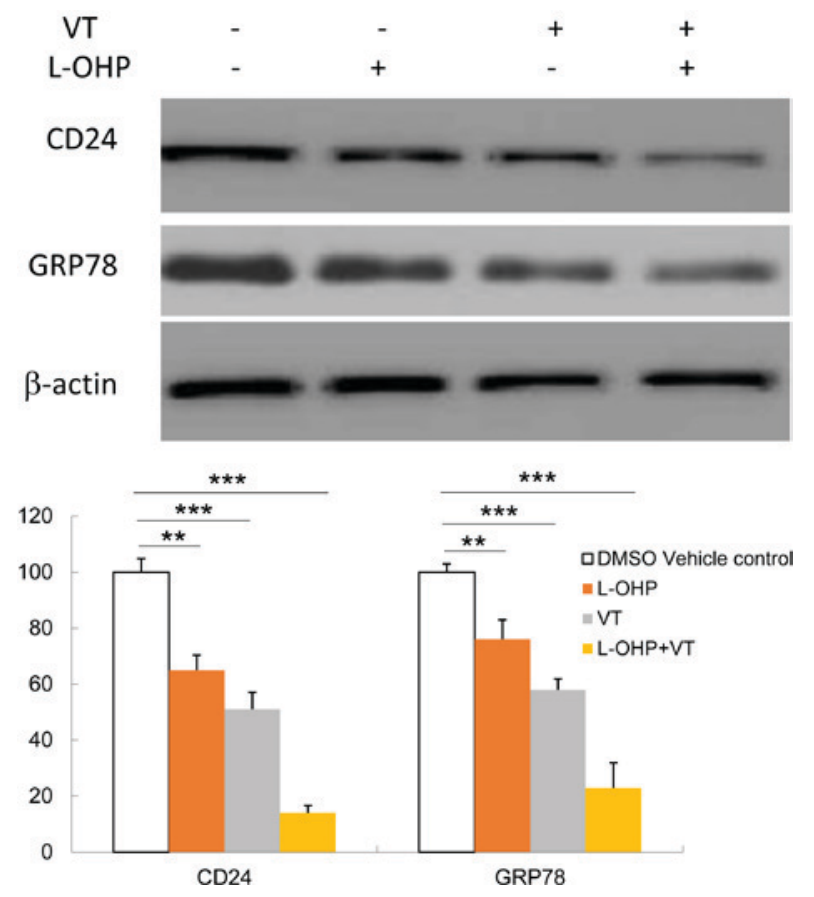

Figure 4. Effect of L-OHP treatment and GRP78 inhibition on CD24 expression. HT29 cells were treated with GRP78 inhibitor VT $(1 \mu \mathrm{g} / \mathrm{ml})$ for $2 \mathrm{~h}$ or L-OHP $(5 \mu \mathrm{M})$ for $24 \mathrm{~h}$ or received combined treatment with VT and L-OHP (VT treatment was $2 \mathrm{~h}$ earlier than L-OHP treatment). Whole-cell lysates were subjected to western blot analysis of CD24 and GRP78 expression. $\beta$-actin was determined to ensure equal protein loading. Values are expressed as the mean \pm standard error of 3 individual experiments. ${ }^{* *} \mathrm{P}<0.01$ and ${ }^{* * *} \mathrm{P}<0.001$ vs. DMSO vehicle control group. GRP78, glucose-regulated protein 78; L-OHP, oxaliplatin; DMSO dimethyl sulfoxide; VT, vomitoxin.

In summary, the results of the present study indicated that CD24 antagonized L-OHP-induced cytotoxicity and that GRP78 was involved in this process. In addition, the potential role of GRP78 in the regulation of the sensitivity of CRC cells to L-OHP-induced cytotoxicity was examined. It was indicated that GRP78 physically interacts with CD24 and that downregulation of GPR78 using GPR78 synthesis inhibitor sensitized CRC cells to L-OHP-induced cytotoxicity, at least in part by inhibition of CD24.

\section{Discussion}

CRC is the fourth most common cause of cancer-associated mortality after lung, gastric and liver cancer.L-OHP is widely used as the first-line chemotherapeutic agent in patients with CRC. However, resistance of human CRC cells to the available chemotherapeutic agents is considered a major obstacle to successful treatment (34). Therefore, a better understanding of the molecular mechanisms underlying L-OHP resistance may be helpful in developing more effective treatments for CRC.

The present study demonstrated that the expression of CD24 contributes to the resistance of CRC cells against L-OHP-induced cytotoxicity $(2,13)$. The HT29 cell line with high expression of CD24 and the SW480 cell line with low expression of CD24 were selected to explore the role of CD24 in modulating the cytotoxic effect of L-OHP on CRC cells. The SW480 cells were more sensitive to L-OHP than HT29 cells. Furthermore, knockdown of CD24 using siRNA sensitized the HT29 cells to L-OHP and ectopic expression of CD24 made SW480 cells resistant to L-OHP. These results indicate that CD24 expression antagonizes the cytotoxic effect of L-OHP. Decades of research have demonstrated that CD24 promotes cancer cell proliferation and migration; furthermore, overexpression of CD24 is associated with enhanced chemoresistance and poor prognosis (1-6). Therefore, CD24 has been described as a novel predictor of responsiveness to chemotherapy and an adverse prognostic marker in the context 
A

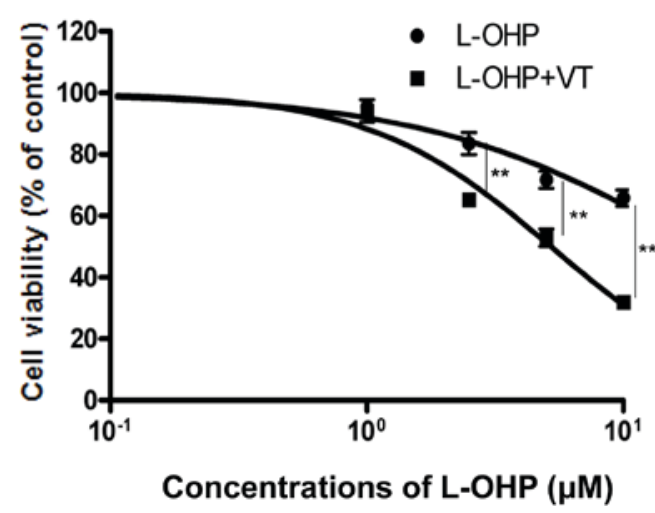

B

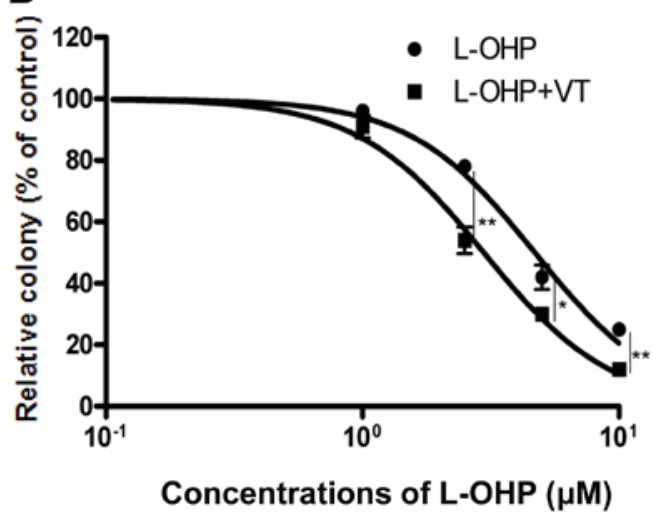

Figure 5. Inhibition of GRP78 sensitizes HT-29 cells to L-OHP-induced cytotoxicity in cell viability and colony formation assays. HT29 cells were treated with or without GRP78 inhibitor VT $(1 \mu \mathrm{g} / \mathrm{ml})$ for $2 \mathrm{~h}$, followed by incubation with L-OHP at different concentrations for another $24 \mathrm{~h}$. (A) Cell viability was evaluated with a CellTiter-Blue assay. (B) The cells were seeded at a low density and cultured for another 10-14 days; the number of colonies was counted and expressed as a percentage of colony growth relative to that in the vehicle-treated control. Values are expressed as the mean \pm standard error of three independent experiments. Statistical significance compared with the L-OHP group $\left({ }^{*} \mathrm{P}<0.05,{ }^{* *} \mathrm{P}<0.01,{ }^{* * *} \mathrm{P}<0.001\right)$. GRP78, glucose-regulated protein 78 ; L-OHP, oxaliplatin; VT, vomitoxin.

of several malignancies (3). The present study confirmed that CD24 overexpression antagonizes L-OHP-induced cytotoxicity; this may be a possible mechanism for the acquisition of L-OHP resistance by CRC cells. Identifying the underlying regulatory mechanisms of CD24 expression will help to improve the effectiveness of L-OHP.

A previous study by our group identified a series of potential CD24-interacting proteins, which included GRP78. The present study revealed that GRP78 was coordinately expressed with CD24 expression. In HT29 cells, GRP78 and CD24 were highly expressed, and suppression of GRP78 using a pharmacological inhibitor resulted in a significant decrease in CD24 expression. The co-IP assay indicated that GRP78 physically associates with CD24. Therefore, it was deduced that GRP78 may directly promote CD24 expression. Co-IP assay revealed that L-OHP treatment decreased the expression of GRP78 and CD24, which may be due to suppression of the interaction between GRP78 and CD24 by L-OHP. Follow-up experiments are required to confirm this hypothesis. Treatment of HT29 cells with L-OHP induced a significant downregulation of CD24 expression, while GRP78 expression was also downregulated. Therefore, L-OHP maybe reduce the interaction between GRP78 and CD24. In addition, combined treatment with L-OHP and GRP78 inhibitor decreased the expression of CD24 to a great extent compared with separate drug treatments. However, these results are preliminary, and follow-up experiments are required for verification. It was hypothesized that inhibition of GRP78 by VT sensitizes HT29 cells to L-OHP, which may result in a higher cytotoxic effect. The cytotoxicity assay indicated that GRP78 inhibitor sensitized HT29 cells to L-OHP, which confirmed the present hypothesis. However, we have only completed some preliminary experiments, follow-up experiments still need to do to verify the results in the future.

In conclusion, the present results indicate that CD24 antagonizes L-OHP-induced cytotoxicity and that upregulation of CD24 may be a possible resistance mechanism in CRC cells. GRP78 was indicated to promote CD24 expression and may be a promising target of anti-tumor therapy. Sensitization of CRC cells to L-OHP-induced cytotoxicity by inhibition of GRP78 was closely associated with down-regulation of CD24. Thus, combination of drugs capable of suppressing GRP78 may enhance the effectiveness of L-OHP in the treatment of CRC and may help improve the prognosis of patients with CRC.

\section{Acknowledgements}

The authors would like to thank Professor Hans-Peter Altevogt (Department of Translational Immunology, German Cancer Research Centre, Heidelberg, Germany) for providing anti-CD24-SWA11 monoclonal antibody. The antibody was generated in this lab (32).

\section{Funding}

This work was supported by the National Natural Science Foundation of China (grant no. 81572938).

\section{Availability of data and materials}

The analyzed data sets generated during the study ar the corresponding author on reasonable request.

\section{Authors' contributions}

XW conceived and designed the experiments. JX, YC, SH and FC performed the experiments. SH analyzed the data.

\section{Ethical approval and consent to participate}

Not applicable.

\section{Consent for publication}

Not applicable.

\section{Competing interests}

The authors declare that they have no competing interests. 


\section{References}

1. Bretz N, Noske A and Keller S, Erbe-Hofmann N, Schlange T, Salnikov AV, Moldenhauer G, Kristiansen G and Altevogt P: CD24 promotes tumor cell invasion by suppressing tissue factor pathway inhibitor-2 (TFPI-2) in a c-Src-dependent fashion. Clin Exp Metastasis 29: 27-38, 2012.

2. Keeratichamroen S, Leelawat $K$, Thongtawee T, Narong S, Aegem U, Tujinda S, Praditphol N and Tohtong R: Expression of CD24 in cholangiocarcinoma cells is associated with disease progression and reduced patient survival. Int J Oncol 39: 873-881, 2011.

3. Agrawal S, Kuvshinoff BW, Khoury T, Yu J, Javle MM, LeVea C, Groth J, Coignet LJ and Gibbs JF: CD24 expression is an independent prognostic marker in cholangiocarcinoma. J Gastrointest Surg 11: 445-451, 2007.

4. Kwon MJ, Han J, Seo JH, Song K, Jeong HM, Choi JS, Kim YJ, Lee SH, Choi YL and Shin YK: CD24 overexpression is associated with poor prognosis in luminal A and triple-negative breast cancer. PLoS One 10: e139112, 2015.

5. Tang MR, Wang YX, Guo S, Han SY, Li HH and Jin SF: CD24 expression predicts poor prognosis for patients with cutaneous malignant melanoma. Int J Clin Exp Med 7: 4337-4341, 2014.

6. Wu JX, Zhao YY, Wu X and An HX: Clinicopathological and prognostic significance of CD24 overexpression in patients with gastric cancer: A meta-analysis. PLoS One 9: e114746, 2014.

7. Tanaka T, Terai Y, Kogata Y, Ashihara K, Maeda K, Fujiwara S, Yoo S, Tanaka Y, Tsunetoh S, Sasaki H, et al: CD24 expression as a marker for predicting clinical outcome and invasive activity in uterine cervical cancer. Oncol Rep 34: 2282-2288, 2015.

8. Overdevest JB, Thomas S, Kristiansen G, Hansel DE, Smith SC and Theodorescu D: CD24 offers a therapeutic target for control of bladder cancer metastasis based on a requirement for lung colonization. Cancer Res 71: 3802-3811, 2011.

9. Sagiv E, Starr A, Rozovski U, Khosravi R, Altevogt P, Wang T and Arber N: Targeting CD24 for treatment of colorectal and pancreatic cancer by monoclonal antibodies or small interfering RNA. Cancer Res 68: 2803-2812, 2008.

10. Smith SC, Oxford G, Wu Z, Nitz MD, Conaway M, Frierson HF, Hampton G and Theodorescu D: The metastasis-associated gene CD24 is regulated by Ral GTPase and is a mediator of cell proliferation and survival in human cancer. Cancer Res 66: 1917-1922, 2006.

11. Su D, Deng H. Zhao X, Zhang X, Chen L, Chen X, Li Z, Bai Y, Wang Y, Zhong Q, et al: Targeting CD24 for treatment of ovarian cancer by short hairpin RNA. Cytotherapy 11: 642-652, 2009.

12. Suyama K, Onishi H, Imaizumi A, Shinkai K, Umebayashi M, Kubo M, Mizuuchi Y, Oda Y, Tanaka M, Nakamura M and Katano M: CD24 suppresses malignant phenotype by downregulation of SHH transcription through STAT1 inhibition in breast cancer cells. Cancer Lett 374: 44-53, 2016.

13. Ke J, Wu X, Wu X, He X, Lian L, Zou Y, He X, Wang H, Luo Y, Wang L and Lan P: A subpopulation of CD24 cells in colon cancer cell lines possess stem cell characteristics. Neoplasma 59: 282-288, 2012.

14. Salnikov AV, Bretz NP, Perne C, Hazin J, Keller S, Fogel M, Herr I, Schlange T, Moldenhauer G and Altevogt P: Antibody targeting of CD24 efficiently retards growth and influences cytokine milieu in experimental carcinomas. Br J Cancer 108: 1449-1459, 2013

15. Parker AL, Turner N, McCarroll JA and Kavallaris M: $\beta I I I-t u b u l i n$ alters glucose metabolism and stress response signaling to promote cell survival and proliferation in glucose-starved non-small cell lung cancer cells. Carcinogenesis 37: 787-798, 2016.

16. Zoni E, Chen L, Karkampouna S, Granchi Z, Verhoef EI, La Manna F, Kelber J, Pelger RCM, Henry MD, Snaar-Jagalska E, et al: CRIPTO and its signaling partner GRP78 drive the metastatic phenotype in human osteotropic prostate cancer. Oncogene 17: 4739-4749, 2017.

17. Ogawa H, Kaira K, Takahashi K, Shimizu A, Altan B, Yoshinari D, Asao T and Oyama T: Prognostic role of BiP/GRP78 expression as ER stress in patients with gastric adenocarcinoma. Cancer Biomark 7: 273-281, 2017.
18. Kawiak A, Domachowska A, Jaworska A and Lojkowska E: Plumbagin sensitizes breast cancer cells to tamoxifen-induced cell death through GRP78 inhibition and Bik upregulation. Sci Rep 13: 43781, 2017.

19. Lizardo MM, Morrow JJ, Miller TE, Hong ES, Ren L, Mendoza A, Halsey CH, Scacheri PC, Helman LJ and Khanna C: Upregulation of glucose-regulated protein 78 in metastatic cancer cells is necessary for lung metastasis progression. Neoplasia 28: 699-710, 2016.

20. Gonzalez-Gronow M, Selim MA, Papalas J and Pizzo SV: GRP78: A multifunctional receptor on the cell surface. Antioxid Redox Signal 11: 2299-2306, 2009.

21. Wang M, Wey S, Zhang Y, Ye R and Lee AS: Role of the unfolded protein response regulator GRP78/BiP in development, cancer, and neurological disorders. Antioxid Redox Signal 11: 2307-2316, 2009

22. Rauschert N, Ndlein SB, Holzinger E, Hensel F, Müller-Hermelink HK and Vollmers HP: A new tumor-specific variant of GRP78 as target for antibody-based therapy. Lab Invest 88: 375-386, 2008.

23. Papalas JA, Vollmer RT, Gonzalezgronow M, Pizzo SV, Burchette J, Youens KE, Johnson KB and Selim MA: Patterns of GRP78 and MTJ1 expression in primary cutaneous malignant melanoma. Mod Pathol 23: 134-143, 2010.

24. Fu W, Wu X, Li J, Mo Z, Yang Z, Huang W and Ding Q: Upregulation of GRP78 in renal cell carcinoma and its significance. Urology 75: 603-607, 2010.

25. Xia YZ, Yang L, Xue GM, Zhang C, Guo C, Yang YW, Li SS, Zhang LY, Guo QL and Kong LY: Combining GRP78 suppression and MK2206-induced Akt inhibition decreases doxorubicin-induced P-glycoprotein expression and mitigates chemoresistance in human osteosarcoma. Oncotarget 7: 56371-56382, 2016.

26. Yerlikaya A, Erdogan E, Okur E, Yerlikaya S and Savran B: A novel combination treatment for breast cancer cells involving BAPTA-AM and proteasome inhibitor bortezomib. Oncol Lett 12: 323-330, 2016.

27. Kong DH, Zhang Q, Meng X, Zong ZH, Li C, Liu BQ, Guan Y and Wang HQ: BAG3 sensitizes cancer cells exposed to DNA damaging agents via direct interaction with GRP78. Biochim Biophys Acta 1833: 3245-3253, 2013.

28. Golden EB, Cho HY, Jahanian A, Hofman FM, Louie SG, Schönthal AH and Chen TC: Chloroquine enhances temozolomide cytotoxicity in malignant gliomas by blocking autophagy. Neurosurg Focus 37: E12, 2014.

29. Luvsandagva B, Nakamura K, Kitahara Y, Aoki H, Murata T, Ikeda S and Minegishi T: GRP78 induced by estrogen plays a role in the chemosensitivity of endometrial cancer. Gynecol Oncol 126: 132-139, 2012

30. Gifford JB and Hill R: GRP78 influences chemoresistance and prognosis in cancer. Curr Drug Targets: Jun 15, 2017 (Epub ahead of print).

31. Soni P, Qayoom S, Husain N, Kumar P, Chandra A, Ojha BK and Gupta RK: CD24 and nanog expression in stem cells in glioblastoma: Correlation with response to chemoradiation and overall survival. Asian Pac J Cancer Prev 18: 2215-2219, 2017.

32. Kristiansen G, Machado E, Bretz N, Rupp C, Winzer KJ, König AK, Moldenhauer G, Marmé F, Costa J and Altevogt P: Molecular and clinical dissection of CD24 antibody specificity by a comprehensive comparative analysis. Lab Invest 90 : 1102-1116, 2010

33. Wang X, Zhang Y, Zhao Y, Liang Y, Xiang C, Zhou H, Zhang H, Zhang Q, Qing H, Jiang B, et al: CD24 promoted cancer cell angiogenesis via Hsp90-mediated STAT3/VEGF signalling pathway in colorectal cancer. Oncotarget 7: 55663-55676, 2016.

34. Huang YN, Guo X, You LP, Wang CJ, Liu JQ and Li YL: Lysosome-associated protein transmembrane $4 \beta$ is involved in multidrug resistance processes of colorectal cancer. Oncol Lett 14: 5229-5234, 2017.

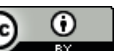

This work is licensed under a Creative Commons Attribution 4.0 International (CC BY 4.0) License. 